\title{
EFEK KONSENTRASI ZAT PENGEMBAN TERHADAP KETUAAN WARNA PADA PENCELUPAN SERAT POLIESTER DENGAN ZAT WARNA DISPERSI
}

\author{
Agus Taufiq \\ Jurusan Teknik Kimia, Fakultas Teknologi Industri, \\ Universitas Islam Indonesia, Jl. Kaliurang Km. 14 Yogyakarta \\ Telepon 0274-895287, Fax. 0274-895007 ext. 148 \\ e-mail : auggie_my@yahoo.com
}

\begin{abstract}
This Research study how far the concentration of carrier agent influence to the dyeing result of of poliester cloth with dyestuff of Resolin Red FB.

Dyeing process conducted with Resolin Red FB 200\% as a dyestuff and four kinds of carrier agent that is metilnaftalena, difenil, triklorbenzena and ortofenilfenol with concentration of carrier agent, from $2 \mathrm{~g} / \mathrm{l}, 4 \mathrm{~g} / \mathrm{l}, 6 \mathrm{~g} / \mathrm{l}$ and $8 \mathrm{~g} / \mathrm{l}$. Hereinafter conducted by examination of colour leveling to the result of dyeing process.

The result show that concentration of carrier agent give an effect to the leveling of colour, that is consentration excelsior yielded the better of colour leveling. This research also get, that triklorbenzena type yield the older colour from orto fenilfenol, metilnaftalena and difenil type, with the optimum concentration reached by $6 \mathrm{~g} / \mathrm{l}$.

Keyword: dispersion, polyester, carrier agent, levelling of colour
\end{abstract}

\section{PENGANTAR}

Sifat fisik yang penting dari serat poliester seperti kristalitas yang tinggi, pengembunan yang terbatas di dalam air dan kekompakannya, menyebabkan kesulitan dalam penyerapan zat warna dispersi oleh serat.

Hal ini diperlihatkan dalam kecepatan difusinya yang rendah di dalam serat. Kecepatan difusi dapat dinaikkan dengan menggunakan zat pengemban atau dengan mencelup pada suhu tinggi.

Penggunaan zat pengemban dalam pencelupan memberikan suatu masalah, karena zat pengemban tersebut mempengaruhi sifat fisik serat polyester oleh karena itu pemakaiannya perlu mendapatkan kontrol. Kekurangan atau kelebihan pemakaian akan menghasilkan warna tidak sesuai dengan yang diinginkan.

Serat poliester memegang peranan penting dalam industri tekstil dewasa ini, demikian pula untuk masa yang akan datang, dengan sifat utamanya enak dipakai dan tahan kusut, maka serat poliester cocok untuk pakaian wanita dan pria. Tetapi serat poliester lebih sukar dicelup dibandingkan dengan serat alam, dan salah satu cara pencelupannya yaitu dengan zat warna dispersi dilakukan menggunakan zat pengemban. Dengan cara ini pencelupan tidak perlu dilakukan dalam suhu tinggi dan dapat lebih cepat, sehingga dengan cara ini dapat dilakukan oleh pabrik dengan kategori sedang. 
Dalam penelitian ini digunakan zat warna Resolin Red FB 200\% dan kain poliester $100 \%$ dengan zat pengemban yang dipilih yaitu yang mempunyai struktur molekul : difenil, metil naftalena, triklorbenzena, ortho fhenil fhenol.

\section{LANDASAN TEORI}

\subsection{Serat Poliester}

Serat poliester dikembangkan oleh J.R. Whinfield dan J.T.Dickson dari Printers Assosiation.I.C.I. di Inggris memproduksi serat poliester dengan nama Terylene dan kemudian Du pont di Amerika pada tahun 1953 juga membuat serat poliester berdasarkan patent dari Inggris dengan nama Dacron. Poliester dibuat dari asam tereftalat dan etilena glikol. Dacron dibuat dari asamnya dan reaksinya dapat ditulis sebagai berikut [ 7 ]:

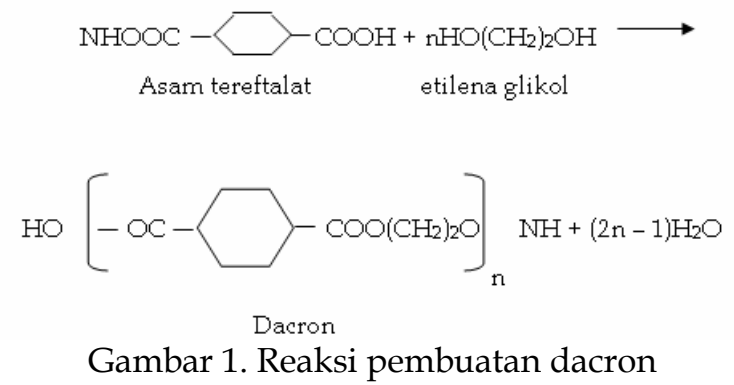

\subsection{Zat Warna Dispersi}

Berdasarkan struktur molekulnya hampir semua zat warna dispersi dapat diklasifikasikan dalam tiga golongan yaitu aminoazobenzena, aminoantrakinon, atau difenilamina. Zat warna dispersi mula-mula ditemukan untuk mencelup serat selulosa. Serat selulosa asetat tidak dapat dicelup langsung dengan zat warna direk atau zat warna asam karena seratnya hidrofob. Serat asetat baru dapat dicelup dengan zat warna direk setelah seratnya dihidrolisa kembali menjadi selulosa dengan soda kaustik, tetapi hasilnya tidak memuaskan.

Zat warna dispersol yang pertama adalah suatu senyawa antrakinon dan S.R.A. merupakan pigmen yang didispersikan. Kedua zat warna tersebut mencelup serat dengan bantuan zat pendispersi. Nama S.R.A. diambil dari zat pendispersi yang dipakai, yaitu asam sulfonisinolat yang kemudian diganti dengan zat pendispersi buatan yang lebih baik. Penemuan zat warna dispersi ini menjadi sangat penting dengan ditemukannya serat sintetik yang sifatnya lebih hidrofob dari pada serat selulosa asetat, seperti serat poliamida, poliester dan serat poliakrilat.

Terutama untuk serat poliester, yang kebanyakan hanya dapat dicelup dengan zat warna nonion yang terdiri dari inti kromofor azo dan antrakinon sedangkan untuk beberapa warna kuning yang penting mengandung gugus difenilamina, seperti terlihat pada contoh-contoh berikut [ 2 ]: 


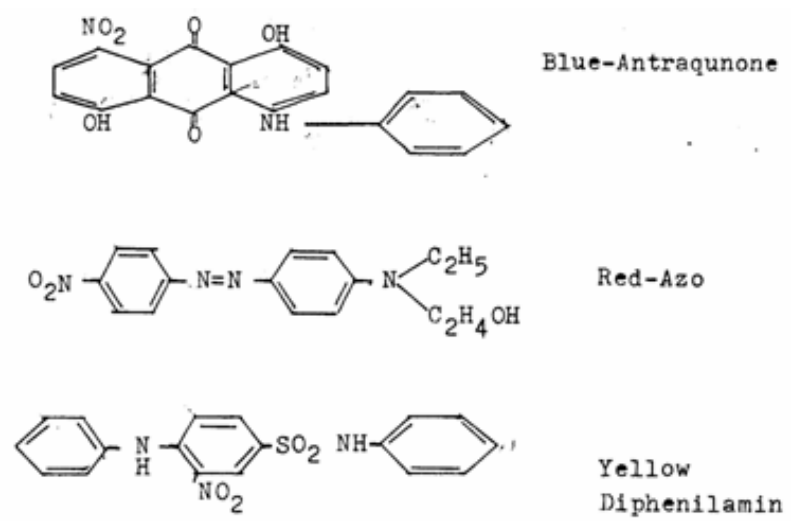

Gambar 2. Inti Kromofor Antrakinon, Azo dan Difenilamina

Sifat-sifat dari zat warna dispersi secara umum dapat ditunjukkan dalam sifat kimia antara lain dalam bentuk dispersi dapat mencelup serat hidrofob; kebanyakan zat warna dispersi mengandung gugus aromatik dan alifatik yang rnengikat gugus fungsional dan bertindak sebagil gugus pemberi atau gugus hydrogen; cenderung untuk rnenyublin pada suhu tinggi dalam fiksasi dengan serat-serat hidrofop yang mempunyai gugus karbonil, gugus fungsional mengalami interaksi dwikutub yang juga rnemberi ketahanan pada zat warna dispersi tersebut.

Sedangkan sifat-sifat fisika zat warna dispersi banyak dipengaruhi oleh gugus substitusi yang ada di samping sifat-sifat dari struktur dasar. Gugus-gugus $\mathrm{OH}$ dan -NH mempunyai kecenderungan bertambah dalam air.

\subsection{Zat Pendispersi}

Zat pendispersi memegang peranan penting dalam pencelupan dengan zat warna dispersi karena dalam pemakaiannya memerlukan zat pendispersi untuk membentuk larutan dispersi zat warna yang dikehendaki. Zat pendispersi mempunyai fungsi ganda di dalam pembuatan dan pemakaian zat warna dispersi, yaitu memecah partikel zat warna yang beragresi dan menstabilkan larutan dispersi zàt warna tersebut.

Zat pendispersi yang pertama kali dipakai ialah asam resin oleat yang disulfonkan atau asam sulforisinolat, sehingga seri pertama zat warna dispersi dinamakan juga sulforisinolat colours, zat pendispersi umumnya terdiri dari senyawa-senyawa dengan berat molekul tinggi atau senyawa polimer. Gugus polar atau gugus ion dan gugus non polar atau non-ion terletak bergantian sepanjang rantai molekul. Kadang-kadang dalam bentuk rantai pendukung dan gugus non polar dengan gugus polar pada sisinya sepanjang rantai molekul. Hasil penelitian Bird dkk. tentang pengaruh penambahan zat pendispersi ke dalam larutan celup, hasilnya ternyata rnenunjukkan bahwa zat warna dispersi dapat dibuat larut dalam medium air [ 4 ].

Namun demikian perlu diperhatikan bahwa sampai titik tertentu tingkat pencelupan dapat ditingkatkan dengan. penambahan zat pendispersi, tetapi bila 
penambahan berlebihan maka kelarutan zat warna menjadi besar dan tingkat penyerapan zat warna menjadi rendah.

\subsection{Zat Pengemban}

Zat pengemban sebagai suatu zat pembantu kimia yang kelarutannya dalam air sangat terbatas, akan melancarkan penetrasi dan penyerapan zat warna. Zat pengemban yang diperdagangkan mengandung zat pengemulsi yang berfungsi untuk mempertahankan kestabilan zat pengemban dan agar teremulsi dengan baik di dalam larutan. Zat pengemban mempunyai bermacam-macam struktur kimia, beberapa diantaranya yang banyak dipakai di dalam pencelupan serat poliester adalah difenil, o-fenilfenol, metliriaftalena, triklorbenzena dll.

Kelarutan zat pengemban memegang peranan penting dalam mekanisme pencelupan dengan zat pengemban. Hasil penelitian Pidment Section AATCC menunjukkan bahwa kelarutan zat warna dispersi dalam zat pengemban cukup tinggi, yaitu sekitar $20-30 \%$ terhadap berat zat pengemban. Zat pengemban diperlukan dalam pencelupan serat-serat sintetik hidrofob untuk mendapatkan difusi zat warna. Karena mempunyai fungsi mempercepat pencelupan maka zat pengemban disebut juga sebagai "dyeing accelerant" atau pendorong pencelupan. Vickerstaff menyatakan bahwa zat pengemban dapat memperbesar penyerapan zat warna oleh serat hidrofob. Namun demikian tidak ada zat pengemban yang mempunyai sifat-sifat yang memuat secara keseluruhan baik dalam hal harga, efektifilas, stabi litas larutan celup,non volatilitas kemudahan di hilangkan dan kemampuan untuk mencelup dengan semua zat warna dipersi. Masing-masing zat pengemban mempunyai kelebihan-kelebihan dan kekurangan-kekurangan tersendiri terhadap macam macam bahan dan zat warna dispersi [ 4 ].

Sebagai ukuran baik buruknya suatu zat pengemban, nilai daya guna relatif dapat digunakan walaupun belum mewakili keseluruhan sifat-sifat zat pengemban, tetapi sudah dianggap memadai oleh karena berhubungan dengan penyerapan. Seperti diteliti oleh Vickerstaff tentang daya guna relatif dari zat pengemban yang bersifat dapat larut dan tidak dapat larut. Untuk jenis larut dipakai fenol sedangkan jenis tidak larut dipakai difenil. Dalam percobaan ini dicari konsentrasi dari kedua macam zat pengemban tersebut untuk mendapatkan penyerapan yang seimbang dan zat warna yang sama. Hasil yang didapat ternyata menunjukan perbedaan yang besar yaitu Difenil 0,75 g/1 dan Fenol 20 g/l. Sementara itu Derbyshire dkk. juga melakukan percobaan tentang penentuan daya guna relatif bermacam-macam zat pengemban dengan jalan membagi pemakalan 1 gram zat pengemban (L\%) dengan kandungan zat pengemban murni dari contoh uji komersil yang di pakai (E\%), sebagaimana ditunjukkan pada formula berikut [3] :

$$
R E=\frac{L \%}{E}=\text { Kons tanta }
$$

Pada umumnya zat pengemban bersifaf racun, oleh karena itu penghisapan terhadap uapnya harus dihindarkan. Dalam pemakaian, perlu diperhatikan kestabilan emulsinya, karena emulsi zat pengemban yang pecah sering menimbulkan kesulitan di dalam pencelupan. Dalam penelitian ini digunakan 
empat macam zat pengemban, yang dipilih berdasarkan perbedaan struktur molekulnya, yaltu zat pengemban dengan struktur molekul ortofenilfenol; difenil; trikhlorbenzena dan metilnaftalena.

\subsection{Pencelupan dengan Adanya Zat Pengemban}

Dengan adanya zat pengemban, akan membantu serat (co-fibre) sehingga mempertinggi kelarutan zat warna dalam serat tersebur (Zimmerman et al). Dalam hal ini, mekanisme kerja zat pengemban adalah mengurangi gaya gaya intermolekuler diantara rantai-rantai molekul poliester, sehingga memperbesar pergerakan rantai molekul serat. Akibatnya menyebabkan molekul-molekul zat warna menetrasi ke dalam serat lebih cepat. Keefektifan dari zat pengemban tergantung pada konsentrasinya dalam serat dan konsentrasinya dalam bak pencelupan.

Sedangkan mekanisme pencelupan sistem serap dengan zat warna dispersi pada serat polyester dapat diterangkan sebagai benikut : Zat warna dispersi berpindah dari keadaan agregat dalam larutan celup, masuk ke dalam serat sebagai bentuk molekuler. Pigmen zat warna dispersi yang larut dalam air dalam jumlah yang sedikit sangat mudah terserap oleh serat. Sedangkan bagian yang tidak larut merupakan timbunan zat warna yang sewaktu-waktu akan larut untuk mempertahankan kesetimbangannya.

Zat warna dispersi di dalam larutan pencelupan terdispersi menjadi partikel-partikel dengan berbagai ukuran. Hal ini terjadi karena partikel partikel tersebut di dalam larutan bergerak, yang disebut gerakan Brown, sehingga dapat terjadi difusi zat warna ke dalam serat. Partikel ukuran terkecil yang disebut zat warna dispersi molekul tunggal, sangat mudah terserap oleh serat [ 4 ].

Di dalam larutan pencelupan harus terdapat larutan zat warna dispersi yang jenuh terus menerus dan sistem dispersi akan tetap jenuh selama masih terdapat partikel tunggal. Oleh karena itu untuk mempertahankan kesetimbangan di dalam larutan pencelupan setelah partikel molekul tunggal terserap oleh serat, rnaka timbunan zat warna yang merupakan partikel besar akan pecah menjadi molekul tunggal. Dengan demikian kesetimbangan antara distribusi zat warna di dalam serat dan zat warna di dalam larutan dengan konsentrasi zat warna dalam serat selalu tetap. Perbandingan ini disebut tetapan partisi. Distribusi zat warna dalam fasa serat dan larutan dapat dilukiskan secara teoritis dengan isoterm adsorpsi. Isoterm adsorpsi dari zat warna dispersi di dalam serat dan di dalam larutan mengikuti isoterm Langmuir.

Adapun skema mekanisme pencelupan dengan zat warna dispersi dapat ditunjukkan seperti pada gambar berikut [ 1 ]: 


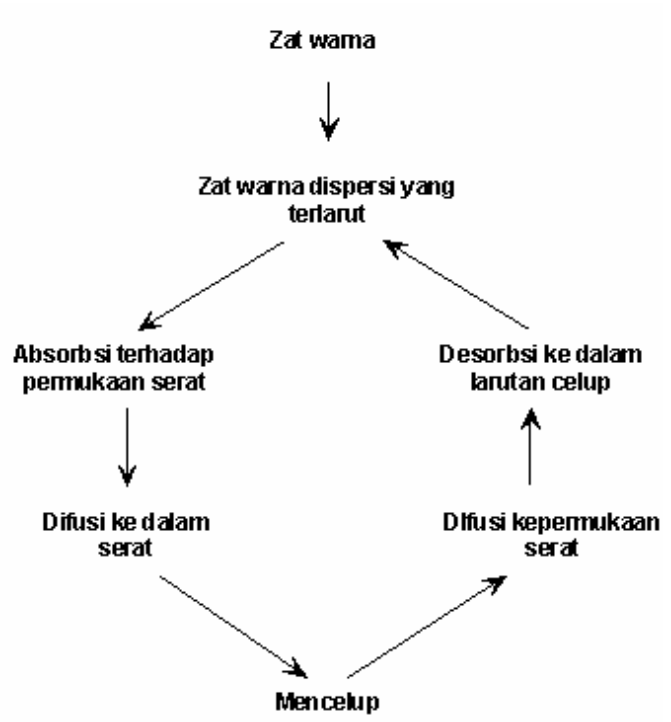

Gambar 3. Mekanisme Pencelupan dengan Zat Warna Dispersi

Secara umum terjadi tiga macam mekanisme yang menyebabkan zat warna dispersi melekat (mewarnai) serat poliester yaitu [1]:

a. Pemindahan zat warna dispersi karena persinggungan zat warna dispersi langsung di pindahkan melalui singgungan dengan serat, peristiwa ini adalah pelarutan padatan zat warna dispersi ke dalam serat.

b. Pemindahan zat warna dispersi melalui medium. Disini persinggungan disiptakan oleh lapisan zat pembantu yang digunakan di dalam larutan yang leleh disekeliling serat pada temperatur termosol. Zat warna dispersi larut dalam lelehan tersebut dan diabsorbsi oleh serat poliester.

c. Pemindahan zat warna dispersi melalui fasa uap. Zat warna dispersi pada temperatur termosol menguap dan uap ini akan diabsorbsi oleh poliester. Dari percobaan-percobaan ternyata mekanisme ketiga ini yang paling dominan. Hal ini nyata terutama pada proses kain campuran poliester selulosa, dimana $\pm 70 \%$ dari larutan benam peras dihisap oleh komponen kain selulosa.

\subsubsection{Metode Pencelupan dengan Suhu Mendidih}

Cara ini merupakan alternatif dari cara pencelupan yang dikehendaki dengan jalan menaikkan suhu dalam metode ini umumnya berkisar antara $60-100^{\circ}$ C. Dengan cara menaikkan suhu maka waktu pencelupan lebih pendek dan ketuaan warna lebih tinggi, serta pengerjaan lebih mudah, tahan lunturnya lebih baik. Suhu sangat berpengaruh terhadap hasil pencelupan. Penelitian yang dilakukan oleh Hafild dan Brodadust mendapatkan bahwa hasil warna dan kerataan pencelupan juga tergantung pada suhu. 


\subsubsection{Pengaruh Zat Pembantu}

Peranan zat pembantu dalam pencelupan serat poliester dengan cara suhu mendidih lebih penting dari pada dalam pencelupan cara lain. Darbyshre et.al membagi zat pembantu menjadi dua, yaitu jenis zat pembantu yang bersifat sebagai zat pengemban (carrier) dan zat pembantu yang bersifat tidak sebagai zat pengemban (non carrier) [3].

Beberapa pengaruh yang mungkin ditimbulkan oleh suatu zat pembantu dalam suhu mendidih antara lain [6] :

a. Pengaruh terhadap hasil warna.

Jenis zat pembantu meningkatkan hasil warna dari zat warna dispersi yang berdifusi lambat. Tetapi pada jenis zat warna dispersi yang berdifusi cepat (tinggi) hasil warna berkurang tapi meningkatkan kerataan warna.

b. Pengaruh terhadap sifat dispersi.

Beberapa obat tertentu bersifat menaikkan stabilitas dispersi serta mencegah pengendapan.

c. Pengaruh terhadap sifat hasil kerataan pencelupan.

Pengaruh ini terjadi dengan jalan merubah kecepatan pencelupan, meningkatkan sifat migrasi atau kedua-duanya.

d. Peningkatan tempat melekat zat warna.

Teori Increased-Siter menyatakan zat pengemban membuka daerah-daerah di dalam serat yang tidak dapat dimasuki oleh zat warna, karena struktur yang rapat dan kompak. Zat pengemban ini menurunkan derajat kristalin dan menaikkan derajat amorf, sehingga terjadi penambahan daerah amorf.

\section{PERCOBAAN DAN PENGUJIAN}

\subsection{PERCOBAAN}

Pencelupan dilakukan pada kain poliester $100 \%$ dengan zat warna dispersi Resolin Red FB 200\% dengan variabel macam dan konsentrasi zat pengemban, dengan metode pencelupan pada suhu mendidih yaitu $98^{\circ} \mathrm{C}$. Terhadap kain hasil pencelupan selanjutnya dilakukan pengujian ketuaan warnanya.

\subsubsection{Bahan yang dipergunakan :}

- Kain poliester $100 \%$.

- $\quad$ Zat warna dispersi Resolin Red FB 200\%, buatan Bayer.

Zat pengemban yang digunakan ada 4 macam berdasarkan perbedaan struktur molekulnya, yaitu : Matexil CAMN (struktur molekul metilnaftalena); Dilatin TCR (struktur molekul triklorbenzena); Dilatin CMX (struktur molekul difenil) dan Levegal DTE (struktur molekul difenil). 


\subsubsection{Alat-alat yang dipergunakan}

- Gelas piala

- Termometer

- $\quad$ Pipet

- $\quad$ Alat pengukur $\mathrm{pH}$

- $\quad$ Alat pemanas

- $\quad$ Pengaduk dan perlengkapan lainnya

\subsubsection{Resep pencelupan}

- Zat warna dispersi

- Zat pendispersi $: 3 \%$.

- Zat pengemban $: 1 \mathrm{~g} / 1$

- $\quad$ Asam asetat $30 \%$ : sampai $\mathrm{pH}$ larutan $=5$.

- Suhu : $98^{\circ} \mathrm{C}$

- Waktu : 1 jam.

- Vlot $: 1: 10$.

\subsubsection{Prosedur pencelupan}

a. Melarutkan zat warna. Zat warna dispersi dibuat pasta dengan air dingin, kemudian ditambah air panas sehingga terdispersi sempurna.

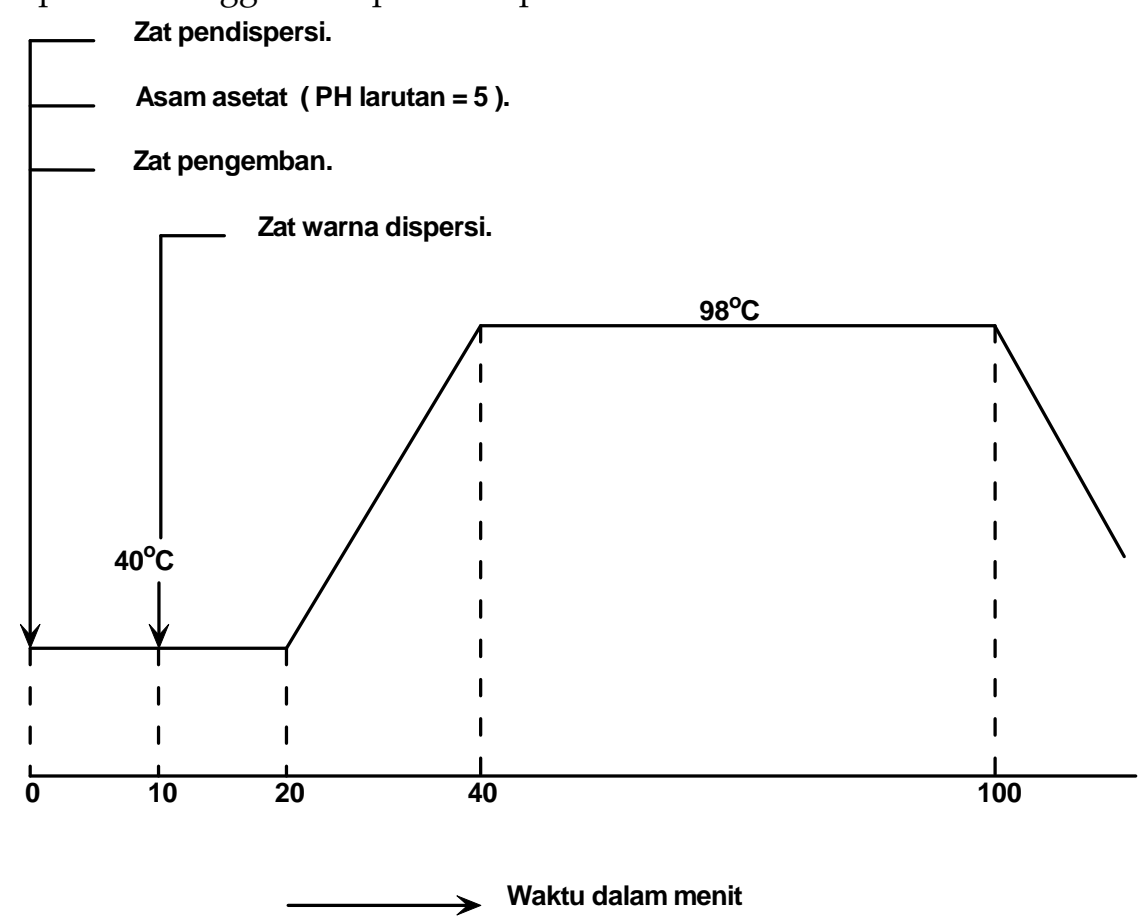

Gambar 4. Skema Pencelupan Poliester dengan Zat Warna Dispersi Cara Pengemban 
b. Pencelupan

Bahan dicelup dalam larutan yang mengandung asam asetat $(\mathrm{pH}$ larutan $=$ 5), zat pengemban, zat pendispersi, pada suhu $40^{\circ} \mathrm{C}$, selama 10 menit. Zat warna yang telah dibuat pasta dimasukkan dalam larutan celup, suhu tetap $40^{\circ} \mathrm{C}$, selama 10 menit. Suhu dinaikkan sampai $90^{\circ} \mathrm{C}$, dicelup pada suhu ini selama 60 menit. Selanjutnya diturunkan perlahan-lahan. Dengan skema pencelupan seperti ditunjukkan pada gambar 4 .

\section{PENGUJIAN}

Setelah dilakukan percobaan-percobaan, selanjutnya dilakukan pengujian untuk mengetahui pengaruh yang terjadi pada kain poliester $100 \%$ dengan menggunakan zat pengemban pada pencelupan zat warna dispersi. Dalam hal ini dari percobaan diuji dan dinilai menurut standar yang berlaku, pengujian dilakukan dalam hal ketuaan warna.

Tabel 1. Hasil Pengamatan Tua Muda Warna oleh 5 Pengamat terhadap Kain Hasil Pencelupan dengan Zat Warna Dispersi pada Beberapa Konsentrasi dan Macam Zat Pengemban

\begin{tabular}{|c|c|c|c|c|c|c|c|}
\hline \multirow{2}{*}{$\begin{array}{l}\text { Zat Warna } \\
\text { Dispersi }\end{array}$} & \multirow{2}{*}{$\begin{array}{l}\text { Macam Zat } \\
\text { Pengemban }\end{array}$} & \multirow{2}{*}{$\begin{array}{c}\text { Konsentrasi ZP } \\
(\mathrm{g} / \mathrm{l})\end{array}$} & \multicolumn{5}{|c|}{ PENGAMAT } \\
\hline & & & $\mathbf{A}$ & B & $\mathrm{C}$ & D & $E$ \\
\hline \multirow{16}{*}{$\begin{array}{c}\text { Resolin Red } \\
\text { FB 200\% }\end{array}$} & \multirow{4}{*}{ Metilnaftalena } & 2 & 2 & 2 & 3 & 3 & 4 \\
\hline & & 4 & 4 & 4 & 4 & 5 & 6 \\
\hline & & 6 & 5 & 5 & 5 & 6 & 6 \\
\hline & & 8 & 4 & 4 & 4 & 5 & 5 \\
\hline & \multirow{4}{*}{ Difenil } & 2 & 3 & 3 & 3 & 3 & 3 \\
\hline & & 4 & 5 & 4 & 4 & 4 & 5 \\
\hline & & 6 & 5 & 5 & 6 & 6 & 6 \\
\hline & & 8 & 4 & 4 & 5 & 5 & 5 \\
\hline & \multirow{4}{*}{ O-fenil fenol } & 2 & 2 & 2 & 2 & 2 & 1 \\
\hline & & 4 & 4 & 4 & 4 & 4 & 4 \\
\hline & & 6 & 6 & 6 & 6 & 5 & 5 \\
\hline & & 8 & 5 & 5 & 5 & 5 & 4 \\
\hline & \multirow{4}{*}{ Triklorbenzena } & 2 & 3 & 3 & 3 & 3 & 2 \\
\hline & & 4 & 5 & 5 & 5 & 5 & 4 \\
\hline & & 6 & 6 & 6 & 6 & 6 & 5 \\
\hline & & 8 & 5 & 5 & 5 & 5 & 4 \\
\hline
\end{tabular}

Pengujian ini dilakukan untuk menentukan tingkat ketuaan warna serta keseksamaannya terhadap hasil penelitian secara visual. Untuk pengamatan ini yang dipakai adalah metode ranking dengan pengamat banyak ( lima orang ), Dengan hasil pengujian seperti ditunjukkan pada tabel 1 dan tabel 2. Dalam hal ini tingkat kesepakatan dari pengamat diukur dengan cofficient of concordance ( W ). 
Rumus: $W=\frac{S}{\frac{m^{2}\left(n^{3}-n\right)}{12}}$

Dimana : $\mathrm{W}=$ tingkat kesepakatan

$\mathrm{S}=$ jumlah kwadran perbedaan $\left(\Sigma \mathrm{d}^{2}\right)$

$\mathrm{n}=$ jumlah contoh uji

$\mathrm{m}=$ jumlah pengamat

Tabel 2. Hasil Penilaian Ketuaan Warna Kain Hasil Pencelupan dengan Zat Warna Dispersi pada Beberapa Konsentrasi dan Macam Zat Pengemban

\begin{tabular}{|c|c|c|c|c|c|c|}
\hline \multirow{2}{*}{$\begin{array}{c}\text { Zat Warna } \\
\text { Dispersi }\end{array}$} & \multirow{2}{*}{$\begin{array}{l}\text { Macam Zat } \\
\text { Pengemban }\end{array}$} & \multirow[t]{2}{*}{ Ranking } & \multicolumn{4}{|c|}{$\begin{array}{l}\text { Konsentrasi Zat } \\
\text { Pengemban }(g / l)\end{array}$} \\
\hline & & & 2 & 4 & 6 & 8 \\
\hline \multirow{8}{*}{$\begin{array}{c}\text { Resolin Red } \\
\text { FB 200\% }\end{array}$} & \multirow{2}{*}{ Metil Naftalena } & Rank total & 14 & 23 & 27 & 22 \\
\hline & & Rank akhir & 3 & 5 & 6 & 4 \\
\hline & \multirow{2}{*}{ Difenil } & Rank total & 15 & 22 & 28 & 23 \\
\hline & & Rank akhir & 3 & 4 & 6 & 5 \\
\hline & \multirow{2}{*}{ Orto-fenilfenol } & Rank total & 9 & 20 & 28 & 24 \\
\hline & & Rank akhir & 2 & 4 & 6 & 5 \\
\hline & \multirow{2}{*}{ Trikhlorbenzena } & Rank total & 14 & 24 & 29 & 23 \\
\hline & & Rank akhir & 3 & 5 & 6 & 4 \\
\hline
\end{tabular}

\section{PEMBAHASAN}

Hasil penelitian menunjukkan bahwa macam dan konsentrasi zat pengemban berpengaruh terhadap ketuaan warna. Zat warna Resolin Red FB $200 \%$, dengan koefisien difusi rendah, merupakan salah satu zat warna dengan molekul besar, sehingga dengan demikian molekul zat warna sukar untuk berdifusi ke dalam serat. Untuk mernpemudah difusi ini ada dua alternatif yang dapat dikerjakan yaitu dengan penambahan zat pengemban atau dengan menaikkan suhu pencelupan.

Makin tinggi konsentrasi zat pengemban yang digunakan, sampai batas optimum penggunaannya, maka akan dihasilkan warna yang makin tua. Adanya zat pengemban di dalam serat akan mengurangi gaya - gaya intermolekuler diantara rantai molekul poliester, sehingga memperbesar pergerakan rantai molekul serat, akibatnya molekul-molekul zat warna berdifusi ke dalam serat lebih cepat.

Dengan makin banyaknya zat pengemban yang berada di dalam rongga larutan, maka makin banyak pula zat warna molekul tunggal yang tersedia sehingga akan mempercepat difusi zat warna ke dalam serat. Di samping itu dengan makin tingginya konsentrasi zat pengemban maka mengkeret kain makin besar artinya serat poliester makin menggembung, akibatnya rnemudahkan partikel zat warna untuk berdifusi ke dalam serat.

Dan hasil percobaan terlihat bahwa untuk pencelupan suhu mendidih dari zat warna Resolin Red FB 200\%, pemakaian zat pengemban yang optimum untuk 
ketuaan warna adalah $6 \mathrm{~g} / \mathrm{l}$. Pemakaian yang relatif banyak ini mungkin karena molekul zat warna Resolin Red FB 200\% yang besar dan difusinya lambat sehingga membutuhkan zat pengemban yang cukup banyak di dalam pencelupan pada suhu mendidih.

Pemakaian zat pengemban yang berlebih dari konsentrasi optimum, akan mengakibatkan warnanya lebih muda. Hal ini dimungkinkan karena terjadinya fasa ke tiga yaitu fasa zat pengemban dan zat yang larut di dalamnya sehingga zat warna akan lebih tertarik dalam rongga larutan, dengan demikian akan mengurangi nilai warna.

Ketuaan warna yang didapat pada hasil pencelupan dengan zat pengemban triklorbenzena $>(\mathrm{o}$-fenilfenol $=$ difenil $)>$ metilnaftalena. Hal ini terjadi karena kemampuan menggembungkan serat poliester oleh zat pengemban triklorbenzena $>$ difenil > metilnaftalena.

\section{SIMPULAN}

- Konsentrasi dan macam zat pengemban dalam pencelupan serat polyester dengan zat warna dispersi Resolin Red FB 200 \% berpengaruh terhadap ketuaan warna.

- Untuk pencelupan suhu mendidih dengan volt 1 : 10 , pemakaian zat pengemban yang terbaik adalah pada konsentrasi $6 \mathrm{~g} / 1$ dan pada kondisi ini zat pengemban triklorbenzena menghasilkan ketuaan warna yang terbaik dibandingkan dengan zat pengemban o-fenilfenol, difenil dan metilnaftalena.

- $\quad$ Pemakaian zat pengemban yang melebihi dari konsentrasi optimum akan menghasilkan warna yang lebih muda.

\section{REKOMENDASI}

Untuk mendapatkan hasil pencelupan yang baik dalam pencelupan kain polyester 100\% dengan zat warna Resolin Red FB 200\% dengan resep seperti pada penelitian ini maka disarankan menggunakan zat pengemban triklorbenzena dengan konsentrasi $6 \mathrm{~g} / 1$.

\section{PUSTAKA}

[1] Anonimus. (1981) Mekanisme Pencelupan Serat Poliester, Majalah Arena Tekstil, No. 7/1981, Institut Teknologi Tekstil, Bandung, halaman 43 - 44

[2] Bucholz,S. Schonpflug and Wurz,A. (1976) Finishing of Polyester Fibres and Polyester Fibres Blends BASF, halaman 241

[3] Derbyshire, A.N. et.al. (1972) Role of Auxilary Products in H.T. Dyeing of P lymer, Journal of Society Dyes and Ca lourists

[4] Fortess F, Lynn E.J. (1981) Advancs in Textile Processing, Volume 1, Textile Book Publisher, N.Y.

[5] Hermann, L. (1981) Polyester Fibres, Chemistry and Technology, Wiley Interscience, N.Y., halaman 382-386

[6] Salihima A., Et al. (1978) Pedoman pengelantangan dan pencelupan, Institut Teknologi Tekstil, Bandung, halaman 193 
[7] Soeprijono,P. (1974) Serat-serat Tekstil, cetakan ke dua, Institut Teknologi Tekstil, Bandung 